\title{
Ring-Shaped Corneal Stromal Opacities after Corneal Cross-linking with Riboflavin and Ultraviolet A Irradiation for Keratoconus
}

\author{
George D Kymionis, Aliki N Limnopoulou, Nela Stojanovic, Argyro D Plaka, Vardhaman P Kankariya
}

\begin{abstract}
A 32-year-old female patient with progressive keratoconus in her right eye was treated with simultaneous customized photoreactive keratoctomy (PRK) and corneal cross-linking (CXL) with riboflavin and Ultraviolet A (UVA) irradiation. Ten days after the procedure, the patient was presented with foreign body sensation, mild ring-shaped corneal infiltration with vascularization at the limbus and Trantas dots at slit-lamp examination along with conjunctival injection and papillary reaction. One month postoperatively, the conjunctival injection decreased but the limbus vascularization and circular infiltration remained. Five months postoperatively, there were no subjective complains and slit-lamp examination revealed circular pseudogerontoxon more dense superiorly. Bestcorrected visual acuty (BCVA) remained 20/20 and corneal topography remained stable. R ing-shaped intrastromal corneal infiltrate could appear after simultaneous PRK-CXL for progressive keratoconus without interfering with the stiffening effect of the procedure.
\end{abstract}

Keywords: Cross-linking complications, Keratoconus, Ringshaped opacities.

How to cite this article: Kymionis GD, Limnopoulou AN, Stojanovic N, Plaka AD, Kankariya VP. Ring-Shaped Corneal Stromal Opacities after Corneal Cross-linking with Riboflavin and UItraviolet A Irradiation for Keratoconus. Int J Kerat Ect Cor Dis 2012;1(2):140-143.

\section{Source of support $\mathrm{Nil}$}

\section{Conflict of interest: None}

\section{INTRODUCTION}

Corneal collagen cross-linking ( $C X L)$ with photosensitizer riboflavin and ultraviolet $A$ (UVA) irradiation is a new technique for stabilizing progressive keratoconus and iatrogenic keratectasia after laser in situ keratomileusis. This procedure stimulates formation of intrafibrillar and interfibrillar covalent bonds by photosensitized oxidation, which results in increased biomechanical stability and increased rigidity of cornea. ${ }^{1-3}$ Other treatment modalities available for keratoconus include rigid gas permeable (RGP) contact lenses, implantation of intrastromal corneal rins segments (INTA CS), lamellar and penetratin keratoplasty. ${ }^{4,5}$ Several combined procedures have been proposed to optimize the CXL outcomes, such as conductive keratoplasty or implantation of Intacs followed by CXL but it seems that the most effective is the combination of customized photorefractive keratectomy (PRK) followed by CXL..$^{6-9}$
Several adverse events have been reported in the literature following corneal CXL including bacterial keratitis, herpetic keratitis and keratitis from acanthamoeba and pseudomonas. ${ }^{10-14}$ The most common complication after simul taneous PR K - CX L is the formation of posterior linear corneal stromal haze. ${ }^{16}$

We present a patient with pseudogerontoxon after corneal collagen CXL with riboflavin and UVA irradiation for keratoconus treatment.

\section{CASE REPORT}

A 32-year-old female patient was referred to the Institute of Vision and Optics at the University of Crete for keratoconus treatment in her right eye. The uncorrected visual acuity at presence was 20/40 in the right eye and 20/ 20 in the left eye. The best corrected visual acuity (BCVA) was $20 / 20$ bilaterally with manifest refraction OD +0.50 $2.75 \times 75^{\circ}$ and $\mathrm{OS}+0.50-0.25 \times 125^{\circ}$. Topography showed inferior steepening bilaterally, but the comparison with previous topographies reveal ed progression of keratoconus only in the right eye. K eratometry readings at her right eye were $K 1: 48.98 \mathrm{D}$ at $141^{\circ}$ and $\mathrm{K} 2: 45.42$ at $51^{\circ}$ ( $G$ alilei dual Scheimpflug imaging, Zimmer Ophthalmics, Port, Switzerland). Central corneal thickness was: OD: $424 \mu \mathrm{m}$ and OS: $450 \mu \mathrm{m}$. Preoperative endothelial cells count was $2,207 \mathrm{cell} / \mathrm{s} / \mathrm{mm}^{2}$ in her right eye and $2,679 \mathrm{cell} / \mathrm{s} / \mathrm{mm}^{2}$ in her left eye. The patient had no history of previous intraocular or corneal surgery, or autoimmune systemic disease. Though she had history of seasonal allergic rhinitis she denied having an allergic keratoconjunctivitis in the past. Slit-lamp examination revealed clear corneas in both eyes without stromal infiltrates or epithelial defects. There were no signs of blepharitis or meibomian glands dysfunction. Fundus was normal in both eyes of the patient.

Customized photorefractive keratectomy combined with corneal collagen CXL using riboflavin and UVA light was proposed to stabilize the keratoconus progression and improve visual acuity in her right eye. The aim of customized PRK was to remodel the shape of the cornea and to decrease irregular astigmatism. The patient was appropriately informed and gave written informed consent in accordance with institutional guidelines, according to the declaration of Helsinki. 
Corneal $C X L$ was conducted under sterile conditions. The right eye was anesthetized with proparacaine $0.5 \%$ (Alcaine). A $6.5 \mathrm{~mm}$ diameter of the corneal epithelium was removed by transepithelial phototherapeutic keratectomy (t-PTK) at intended $50 \mu \mathrm{m}$. PRK was performed in a $5 \mathrm{~mm}$ diameter with attempted correction 0 to $2.50 \times 51$. B oth PTK and PRK were performed with the same excimer laser Allegretto wave $400 \mathrm{~Hz}$ (WaveLight Laser Technologie A G). A fter PR K, riboflavin was instilled $(0.1 \%$ solution $10 \mathrm{mg}$ riboflavin-5-phosphate in $10 \mathrm{~mL}$ dextran-T-500 20\% solution) repeatedly every 3 minutes for approximately 30 minutes. Penetration of the cornea and presence of riboflavin in the anterior chamber (riboflavin shielding) was monitored by slit-lamp examination. UVA irradiation was performed using an optical system (UV-X illumination system version 1000) with a light source consisting of an array of UV diodes (365 nm) with a potentiometer in series to allow regulation of voltage. B efore treatment, an intended irradiance of $3.0 \mathrm{~mW} / \mathrm{cm}^{2}\left(5.4 \mathrm{~J} / \mathrm{cm}^{2}\right.$ surface dose) was calibrated using a UV light meter at a working distance of $1.0 \mathrm{~cm}$. I rradiance was performed for 30 minutes, corresponding to a dose of $5.4 \mathrm{~J} / \mathrm{cm}^{2}$. During treatment, the riboflavin solution was applied every 5 minutes to saturate the cornea with riboflavin and drops of physiological salt solution were applied every 2 minutes to moisten the cornea. A fter treatment, a bandage contact lens was placed and topical antibiotic/corticosteroid drops tobramycin-dexamethasone (TobraD ex, A Icon L aboratories, Inc) were instilled. The procedure was uneventful.

The patient was examined daily until the epithelium was healed completely. On the fourth day, the bandage contact lens was removed. Postoperative medication included diclofenac sodium $0.1 \%$ (Denaclof; Novartis, Hellas, A thens, Greece) for 2 days as well as antibiotic/ corticosteroid (tobramycin/dexamethasone) drops (Tobradex; A Icon Laboratories, Inc) four times daily and antibiotic ofloxacin (Exocin, Allergan Inc., Irvin, USA) drops 4 times daily until the removal of the bandage contact lens. A fter the removal of the contact lens, patient was prescribed corticosteroid drops (fluorometholone 0.1\%; Falcon Pharmaceuticals, Ltd, Fort W orth, Texas, USA), tapering for the next 20 days. Patient was encouraged to use artificial tears (sodium hyaluronate, preservative free) at least six times per day for 6 months postoperatively.

On the 10th day postoperatively, the patient started to complain of a foreign body sensation along with redness in her treated eye. Slit-lamp examination show ed conjunctival injection, mild edema and papillary reaction. At the periphery of the cornea signs consisted of a stromal ringshaped infiltration with intact epithelium above it, a zone of clear cornea between the infiltrate and the limbus, vascularization, more prominent superiorly and Trantas dots
(Fig. 1). The central cornea was clear and the anterior chamber had no reaction. The UVA was 20/32 and the BCV A $20 / 20$ with $+1.25-1.25 \times 120^{\circ}$. The left, untreated eye had no signs of inflammation. Because of the peripheral location of the corneal stromal infiltrate, an immune etiology was suspected and no corneal scrapings were performed. The fluorometholone $0.1 \%$ drops were discontinued and fucidic acid viscous eye drops twice daily along with chloramphenicol/dexamethasone eyedrops four times daily (with tapering a drop per week), were prescribed.

One month postoperatively, there was a significant decrease in conjunctival injection and edema, with no Trantas dots visible. There was however, a mild circular infiltration and vascularization at limbus. Central cornea in diameter of $7 \mathrm{~mm}$ was still clear. BCV A was not decreased. $K$ eratometry readings at her right eye were $K 1: 46.08 D$ at $130^{\circ}$ and K2: $45.10 \mathrm{D}$ at $40^{\circ}$ (Galilei dual Scheimpflug imaging, Zimmer Ophthalmics, Port, Switzerland). The patient was advised to continue with therapy as prescribed.

Three months after the procedure there was still the circular limbal infiltration present with more discernable infiltration lines superiorly. The infiltration was documented by anterior segment optical coherence tomography (ASOCT). Cyclosporine $0.05 \%$ ophthalmic emulsion two times daily was started al ong with chloramphenicol/dexamethasone eye drops four times daily.

On a 5-month follow-up, the patient had no subjective complains. Her visual acuity remained stable. K eratometry readings at her right eye were $K 1: 44.72 \mathrm{D}$ at $138^{\circ}$ and $\mathrm{K} 2$ : $44.02 \mathrm{D}$ at $32^{\circ}$ (Galilei dual Scheimpflug imaging, Zimmer Ophthalmics, Port, Switzerland) with evident corneal flattening and corneal astigmatism reduction. Slit-lamp examination showed presence of complete circular pseudogerontoxon, more dense superiorly (Fig. 2). The

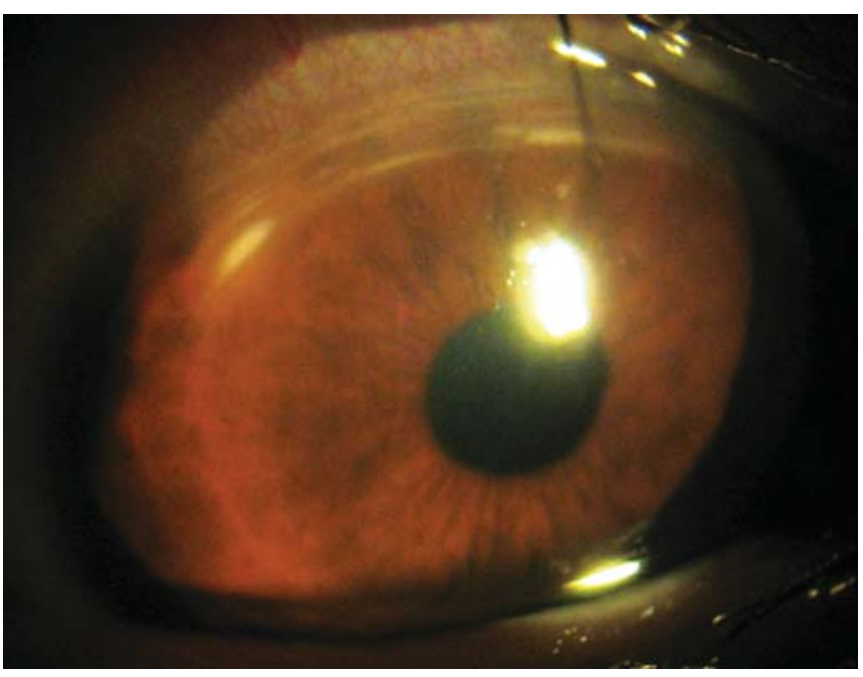

Fig. 1: Slit-lamp examination on the 10th postoperative day showing a stromal ring-shaped infiltration with intact epithelium above it, a zone of clear cornea between the infiltrate and the limbus 


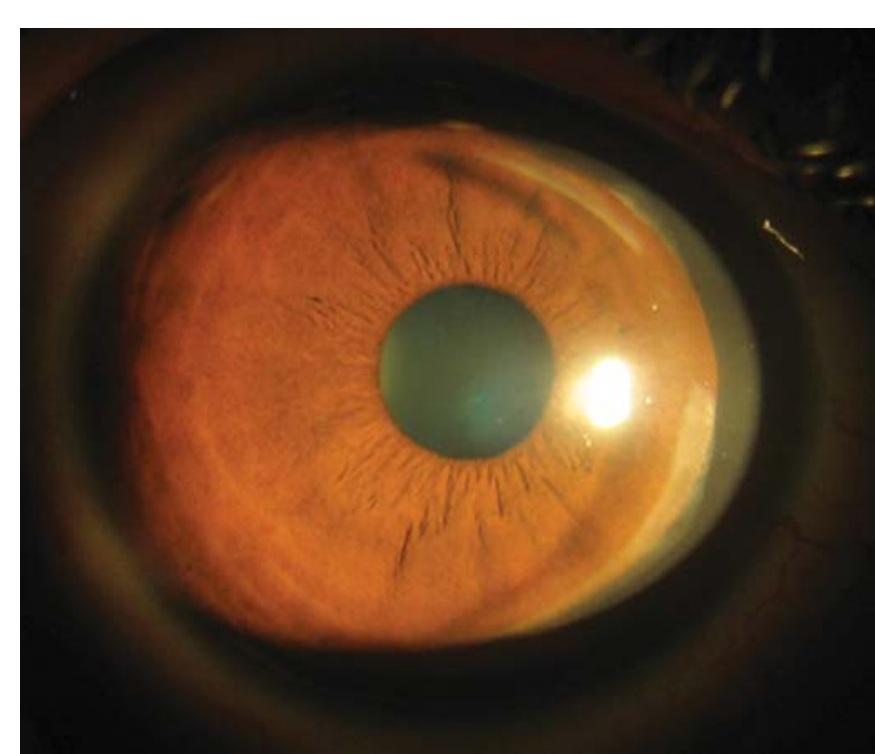

Fig. 2: Slit-lamp examination 5 months postoperatively revealing presence of complete circular pseudogerontoxon, denser superiorly

patient was advised to continue with cyclosporine $0.05 \%$ ophthalmic emulsion two times daily for 2 months. The examination of the left eye remained completely normal.

\section{DISCUSSION}

Corneal collagen CXL by riboflavin and UVA is a new method for the treatment of progressive keratoconus. It has been shown to effectively increase the biomechanical strength of the cornea and to stop or even reverse the progression of keratoconus. The simultaneous PRK-CXL procedure seems to be safe and effective treatment for progressive keratoconus providing improved and stable visual outcome.

Since, $C X L$ represents a relative new surgical technique, it is vital to inform the scientific community about its possible complications or adverse events. Microbial keratitis after $C X L$ has been reported mainly due to the epithelial defect and the use of bandage contact lens, including infection of Pseudomonas aeruginosa, Escherichia coli, acanthamoeba, Streptococcus salivarius, Streptococcus oralis and coagulase-negative Staphylococcus. All these incidents resulted in residual corneal opacities of different severity. In some cases the corneal transplantation was performed in order to control the infection and improve visual outcome of the patients. ${ }^{10-13} \mathrm{~A}$ case of herpetic keratitis with iritis even in patients with no previous history of herpetic disease has been reported in the literature. ${ }^{14}$ Furthermore, induction of diffuse lamellar keratitis after CXL in a patient with post laser in situ keratomileusis ectasia has been recorded..$^{15}$ A nother two potential complications of the technique seem to be the reduction of the corneal endothelial cells in patients with central corneal thickness below $400 \mu \mathrm{m}$ and the appearance of posterior linear stromal haze formation after simultaneous PRK-CXL which gradually becomes less dense and moves anteriorly over a 1 year follow-up period. ${ }^{16,17}$

Peripheral corneal stromal infiltrates could be attributed to an infection, blepharitis-related hypersensitivity to Staphylococcus epidermidis, Mooren's ulcer, Terrien's marginal degeneration and peripheral ulcerative keratitis associated with autoimmune or collagen vascular disease. There have been reports of sterile peripheral corneal stromal infiltrates after photorefractive keratectomy, phototherapeutic keratectomy, laser in situ keratomileusis with the flap being created with a microkeratome or the femtosecond laser and laser-assisted subepithelial keratectomy. They all appeared as early postoperative complication unilaterally or bilaterally and tended to disappear after topical antibiotic and steroid drops al ong with systemic steroid treatment without corneal scarring, affection of the visual acuity, subjective symptoms and with no recurrence. ${ }^{18}$

Sterile corneal stromal infiltrates and melting have been described after the $C X L$ procedure and probably occur as a result of enhanced cell-mediated immunity to staphylococcal antigens deposited at high concentrations in areas of static tear pooling. ${ }^{19}$

Our case may represent a variant of syndromes related to staphylococcal antigen deposition in areas of static tear pooling beneath the bandage contact lens. However, the patient's history of seasonal allergic rhinitis could also explain predisposition to ocular immune response similar to vernal keratoconjunctivitis, triggered by the riboflavin or UVA irradiation.

At a recent publication ${ }^{20}$ the authors reported the appearance of bilateral ring-shaped corneal stromal opacities after CXL for progressive keratoconus which appeared on the first postoperative day and slowly resolved during the following 6 months. Thirty-two months postoperatively the corneal topography revealed corneal flattening and good visual acuity was preserved. The incident could be attributed to the corneal wounding from the $C X L$ with riboflavin which alters cornea's cellularity for until 36 months after the operation.

Pseudogerontoxon is a rare clinical entity usually associated with vernal keratoconjunctivitis. It represents peripheral corneal lipid deposits due to increased vascular permeability caused by corneal allergic inflammation. To our best knowledge this is the first reported case of complete pseudogerontoxon after CXL treatment with no previous history of any type allergic keratoconjunctivitis.

Corneal CXL probably represents the future treatment of corneal ectatic disorders as it may minimize the percentage of patients who need penetrating keratoplasty. 
Ring-shaped Corneal Stromal O pacities after Corneal Cross-linking with R iboflavin and Ultraviolet A Irradiation

The role of the UV light on the immune mechanisms of the cornea warrant further investigation. M ore studies of rare complications of corneal CXL treatment are necessary in order to establish appropriate patient selection, technique performance and improve success rates. Since, the exact pathogenesis of this complication remains unclear, it is vital to be differentiated from an infectious keratitis because the management of the patients is completely different.

\section{REFERENCES}

1. Wollensak G, Spoerl E, Seiler T. Riboflavin/ultraviolet-A induced collagen cross-linking for the treatment of keratoconus. A m J Ophthalmol 2003;135:620-27.

2. Wollensak G. Cross-linking treatment of progressive keratoconus: New hope. Curr Opin Ophthalmol 2006;17:35660.

3. Raiskup-W olf F, Hoyer A, Spoerl E, Pillunat LE. Collagen crosslinking with riboflavin and ultraviolet: A light in keratoconus: Long-term results. J Cataract R efract Surg 2008; 34:796-801.

4. Kymionis GD, Siganos CS, T siklis NS, et al. L ong-term foll ow-up of Intacs in keratoconus. A m J Ophthalmol 2007;143(2):236-44.

5. Tan DT, Por Y M . Current treatment options for corneal ectasia. Curr Opin Ophthalmol 2007;18(4):284-89.

6. Kymionis GD, K ontadakis GA, K ounis GA, et al. Simultaneous topography-guided PRK followed by corneal collagen crosslinking for keratoconus. J Refract Surg 2009;25(9):S807-11.

7. Kanellopoulos AJ, Binder PS. Collagen cross-linking (CCL) with sequential topography-guided PRK: A temporizing alternative for keratoconus to penetrating keratoplasty. Cornea. 2007;26:891-95.

8. Kymionis G, Portaliou D, Kounis G, Limnopoulou A, K ontadakis G, G rentzel os M. Simultaneous topography-guided photorefractive keratectomy foll ow ed by corneal collagen crosslinking for keratoconus. A m J O phthal mol 2011;152(5):748-55.

9. Kymionis G, Grentzelos M , K aravitaki A, K ounis G, K ontadakis G, Y oo S, et al. Transepithelial phototherapeutic keratectomy using a 213 solid-state laser system foll ow ed by corneal collagen cross-linking with riboflavin and UV A irradiation. J Ophthal mol 2010:146543.

10. Pollhammer M, Cursiefen C. Bacterial keratitis early after corneal cross-linking with riboflavin and ultraviolet-A . J Cataract and Refract Surg 2009;35(3):588-89.

11. Pérez-Santonja J J, A rtola A, Javaloy J, A lió J L, A bad J L. $M$ icrobial keratitis after corneal collagen cross-linking. J Cataract and R efract Surg 2009;35(6):1138-40.

12. Namrata S, Praful M, Gurnarinder S, J eewan S. Pseudomonas keratitis after collagen cross-linking for keratoconus: Case report and review of literature. J Cataract R efract Surg 2010;36:517-20.

13. Rama P, Di M atteo F, M atuska S, Paganoni G, Spinelli A. A canthamoeba keratitis with perforation after corneal crosslinking and bandage contact lens use. J Cataract and Refract Surg 2009;35(4):788-91.
14. Kymionis G, Portaliou D, B ouzoukis D, Suh L, Pallikaris A, $M$ arkomanolakis $M$, et al. Herpetic keratitis with iritis after corneal collagen cross-linking with riboflavin and UVA irradiation for keratoconus. J Cataract Refract Surg 2007;33: 1982-84.

15. K ymionis G, B ouzoukis D, Diakonis V, Partaliou D, Pallikaris A, Y oo S, D iffuse lamellar keratitis after corneal cross-linking in a patient with post-laser in situ K eratomileusis corneal ectasia. J Cataract R efract Surg 2007;33:2135-37.

16. Kymionis $G$, Portaliou $D$, Diakonis $V, K$ ontadakis $G, K$ rasia $M$, Papadiamantis $A$, et al. Posterior linear stromal haze formation after simultaneous photorefractive keratectomy followed by corneal collagen cross-linking. Cornea 2010;51:5030-33.

17. Kymionis G, Portaliou D, Diakonis V , K ounis G, Panagopoulou $S, G$ rentzel os M . Corneal collagen cross-linking with riboflavin and ultraviolet: $A$ irradiation in patients with thin corneas. A m J Ophthalmol 2011;20.

18. Lifshitz T, Levy J, M ahler O, Levinger S. Peripheral sterile cornal infiltrates after refractive surgery. J Cataract R efract Surg 2005;31:1392-95.

19. Angunawela RI, A rnalich-M ontiel F, Allan BDS. Peripheral sterile corneal infiltrates and melting after collagen cross-linking for keratoconus. J Cataract R efract Surg 2009;35(3):606-07.

20. Camesasca $F, V$ inciguerra $P$, Seiler $T$. Bilateral ring-shaped intrastromal opacities after corneal cross-linking for keratoconus. J Refract Surg 2011;27(12):913-15.

\section{ABOUT THE AUTHORS}

\section{George D Kymionis (Corresponding Author)}

Department of Ophthalmology, U niversity Hospital of Heraklion University of Crete, Greece, e-mail: kymionis@med.uoc.gr

\section{Aliki N Limnopoulou}

Department of Ophthalmology, Institute of Vision and Optics University of Crete, Greece

\section{Nela Stojanovic}

Department of Ophthalmology, Institute of Vision and Optics University of Crete, Greece

\section{Argyro D Plaka}

Department of Ophthalmology, Institute of Vision and Optics University of Crete, Greece

\section{Vardhaman P Kankariya}

Department of Ophthalmology, Institute of Vision and Optics University of Crete, Greece 


\section{Advertising \& Marketing}

\section{Dedicated to Mark Your Presence in Medical Fraternity}

\section{We Extend Our Effectual Support in Form of:}

\section{Advertisement | Bulk Subscription | Reprints | e-Prints Online Advertisement | Customization | CME | Endorsements}

- Our tactical and conversant publishing team owns a targeted approach to aid you in designing customized market solutions to make you reach key markets and also enjoy business proliferation with our competitive pricing.

- Being world's leading, extensive medical publishers, our state-of-art products and services developed under the close association of local and international medical experts meet your marketing and educational program requirements productively.

- Our growing international associations give you a platform to experience campaign on global front.

- Our PER division includes a team of renowned doctors and specialists to undertake content management for your products and services.

\section{Explore more at:}

www.jaypeejournals.com

(ID) Jaypee Brothers Medical Publishers Pvt. Ltd.

\section{Domestic \& Overseas Operations}

Ahmedabad • Bengaluru $\bullet$ Chennai $\bullet$ Chandigarh $\bullet$ Guwahati $\bullet$ Hyderabad $\bullet$ Kochi $\bullet$ Kolkata

$\bullet$ Lucknow $\bullet$ Mumbai $\bullet$ Mangalore $\bullet$ Nagpur $\bullet$ Patna $\bullet$ Pune $\bullet$ Vijayawada

- London (UK) • Panama City (Panama)

\section{Corporate Office}

4838/24 Ansari Road, Daryaganj, NewDelhi 110 002, India

Phone: 91-11-43574357

e-mail: advertisements@jaypeejournals.com 